\title{
Predictors of low cardiac output syndrome after isolated mitral valve surgery
}

\author{
Manjula Maganti, MSc, Mitesh Badiwala, MD, Amir Sheikh, MD, Hugh Scully, MD, \\ Christopher Feindel, MD, Tirone E. David, MD, and Vivek Rao, MD, PhD
}

Background: Low cardiac output syndrome is defined as the need for a postoperative intra-aortic balloon pump or inotropic support for longer than 30 minutes in the intensive care unit. Mitral valve surgery is increasingly being performed in high-risk patients who might require mechanical circulatory support for low cardiac output syndrome. Therefore the aim of this study was to identify the preoperative predictors of low cardiac output syndrome after mitral valve surgery.

Methods: We conducted a retrospective review of data prospectively entered into an institutional database. Between 1990 and February 2008, 3039 patients underwent isolated mitral valve surgery with or without coronary bypass surgery. The independent predictors of low cardiac output syndrome and operative mortality were determined by means of stepwise logistic regression analysis.

Results: The overall prevalence of low cardiac output syndrome was 7\%. The independent predictors of low cardiac output syndrome were urgency of the operation (odds ratio, 2.9), earlier year of operation (odds ratio, 2.4), left ventricular ejection fraction of less than $40 \%$ (odds ratio, 2.1), New York Heart Association class IV (odds ratio, 2), body surface area of $1.7 \mathrm{~m}^{2}$ or less (odds ratio, 1.6), ischemic mitral valve pathology (odds ratio, 1.6), and cardiopulmonary bypass time (odds ratio, 1.02). The operative mortality was higher in patients with low cardiac output syndrome $(30 \%$ vs $1.3 \%, P<.001)$. Overall operative mortality was $3.4 \%$. The independent predictors of mortality were urgency of the operation (odds ratio, 7.1), renal failure (odds ratio, 4.3), nonuse of polytetrafluoroethylene sutures (Gore-Tex; W. L. Gore \& Associates, Inc, Austin, Tex; odds ratio, 2.1), any reoperative surgical intervention (odds ratio, 1.8), increasing age (odds ratio, 1.03), and cardiopulmonary bypass time (odds ratio, 1.02).

Conclusions: Low cardiac output syndrome is associated with significantly increased morbidity and mortality. Novel strategies to preserve renal function, optimization of pre-existing heart failure symptoms, and use of artificial polytetrafluoroethylene sutures might reduce the incidence of low cardiac output syndrome and lead to improved results after mitral valve surgery. (J Thorac Cardiovasc Surg 2010;140:790-6)

Earn CME credits at

http://cme.ctsnetjournals.org

Low cardiac output syndrome (LCOS) has been previously characterized by our group in patients undergoing isolated coronary bypass surgery and aortic valve surgery. ${ }^{1,2}$ As the proportion of patients undergoing mitral valve surgery with poor preoperative left ventricular (LV) function continues to increase, ${ }^{3}$ we wished to identify the predictors of postoperative LCOS in this population. Furthermore, a sig-

From the Division of Cardiovascular Surgery, Peter Munk Cardiac Center, Toronto General Hospital and the Department of Surgery, University of Toronto, Toronto, Ontario, Canada.

Disclosures: None.

Received for publication June 16, 2009; revisions received Aug 26, 2009; accepted for publication Nov 8, 2009; available ahead of print Feb 12, 2010.

Address for reprints: Vivek Rao, MD, PhD, Toronto General Hospital, 4N-464, 200 Elizabeth St, Toronto, Ontario M5G 2C4, Canada (E-mail: vivek.rao@uhn.on. ca).

0022-5223/\$36.00

Copyright (c) 2010 by The American Association for Thoracic Surgery doi:10.1016/j.jtcvs.2009.11.022 nificant proportion of patients undergoing high-risk mitral valve surgery might be candidates for more advanced surgical therapies for heart failure, including mechanical circulatory support and transplantation. Preoperative prediction of the need for advanced support might allow for a discussion regarding ultimate treatment options. Patients who are screened and found not to be suitable transplant candidates can then be offered short-term temporary support in the hopes of myocardial recovery or long-term implantable devices as destination therapy. Lastly, identification of a high-risk subset might dictate preoperative optimization by the use of diuretic therapy, afterload reduction, and/or intra-aortic balloon pump (IABP) support.

\section{MATERIALS AND METHODS \\ Data Source}

Approval was obtained from our institutional research ethics board to perform a retrospective, clinical chart review. Clinical, operative, and outcome data were collected prospectively in a computerized institutional database on all patients undergoing cardiac surgery. We conducted a retrospective review of our institutional database to identify patients who underwent mitral valve surgery. Between 1990 and February 2008, 

Abbreviations and Acronyms
BMI = body mass index
$\mathrm{CABG}=$ coronary artery bypass grafting
$\mathrm{CBP}=$ cardiopulmonary bypass
IABP = intra-aortic balloon pump
LCOS = low cardiac output syndrome
$\mathrm{LV}=$ left ventricular
LVEF $=$ left ventricular ejection fraction
MI = myocardial infarction
$\mathrm{MR}=$ mitral regurgitation
NYHA $=$ New York Heart Association

3039 patients underwent mitral valve surgery (replacement or repair) with or without coronary bypass surgery.

\section{Explanatory Variables}

Core baseline explanatory variables collected since 1990 included the following: age; sex; LV grade (based on left ventricular ejection fraction [LVEF]: grade $1, \mathrm{LVEF}>60 \%$; grade 2 , LVEF $40 \%$ to $59 \%$; grade 3 , LVEF $20 \%$ to $39 \%$; grade $4, \mathrm{LVEF}<20 \%$ ); urgency of the operation (elective; semiurgent, indicating an operation during the same admission as a cardiac catheterization or a cardiac event; urgent, indicating an operation within 72 hours of an event; or emergency, indicating an operation within 12 hours of an event); New York Heart Association (NYHA) class; mitral valve lesion (stenotic, regurgitant, or mixed, as determined by means of echocardiographic analysis); and infective endocarditis (active endocarditis, active endocarditis with abscess formation, remote endocarditis, or none). LVEF was measured by using ventriculographic or echocardiographic analysis, and the most recent preoperative value was recorded. Other explanatory variables collected to more fully characterize these patients included recent myocardial infarction (MI), diabetes, dyslipidemia, peripheral vascular disease, history of hypertension, preoperative stroke, or transient ischemic attack. Details of this database have been published previously. ${ }^{1-3}$

\section{Study Outcomes}

Our primary outcomes in this study were LCOS and operative mortality. Operative mortality was defined as any postoperative death occurring within 30 days or during the same hospital admission. LCOS was diagnosed if the patient required an IABP to be weaned from cardiopulmonary bypass (CPB) or in the intensive care unit because of hemodynamic compromise. LCOS was also diagnosed if the patient required inotropic medication (either dopamine, dobutamine, milrinone, or epinephrine) to maintain systolic blood pressure at greater than $90 \mathrm{~mm} \mathrm{Hg}$ and cardiac output at greater than $2.2 \mathrm{~L} \cdot \mathrm{min}^{-1} \cdot \mathrm{m}^{-2}$ for at least 30 minutes in the intensive care unit after correction of all electrolyte and blood gas abnormalities and after adjusting the preload to its optimal value. ${ }^{4}$ Afterload reduction was also attempted when possible. Patients who received less than $4 \mu \mathrm{g} / \mathrm{kg}$ dopamine to increase renal perfusion were not considered to have LCOS. Patients who received vasoconstricting medications because of a high cardiac output $\left(\geq 2.5 \mathrm{~L} \cdot \mathrm{min}^{-1} \cdot \mathrm{m}^{-2}\right)$ and low peripheral resistance were also not considered to have LCOS. In patients who received an IABP before surgical intervention, LCOS was determined if they required significant postoperative inotropic support, as described above, in addition to IABP support.

\section{Statistical Analysis}

Statistical analysis was done with SAS 9.2 software (SAS Institute, Inc, Cary, NC). $\chi^{2}$ Tests were used to evaluate categoric data univariately when the minimum number of observations in a category was greater than 5 ; otherwise, the Fisher's exact test was used. Categoric variables were expressed as percentages. Student's $t$ test was used to analyze continuous variables that had normal distribution, and the Wilcoxon rank test was used for variables that had nonparametric distribution. Continuous variables were expressed as means \pm standard deviations. Variables that had a univariate $P$ value of less than .25 or those judged to be clinically important were selected for inclusion in a logistic regression model by means of stepwise selection. Multivariable logistic regression methods were used to calculate factor-adjusted odds ratios and to determine the independent predictors of LCOS and operative mortality. Model discrimination was evaluated by the area under the receiver operating characteristic curve, and calibration was assessed with the Hosmer-Lemeshow goodness-of-fit statistic.

\section{RESULTS \\ Demographics}

The study population $(\mathrm{n}=3039)$ was divided into 3 eras based on the year of the operation $(1990-1995, \mathrm{n}=839$; 1996-2001, $\mathrm{n}=1103$; and 2002-February 2008, $\mathrm{n}=1097$ ) to account for a changing pattern of outcomes over time. LCOS developed in 7\% $(\mathrm{n}=213)$ of all patients. There were 87 patients who received an IABP preoperatively, of whom 43 were deemed to have had LCOS because of the postoperative need for inotropic support. The prevalence of LCOS has decreased over time (Figure 1). The preoperative characteristics of the patients who did and did not have LCOS are provided in Table 1 . The results of univariate analysis revealed that LCOS was significantly associated with year of the operation, increasing age, urgency of the operation, NYHA class, diabetes mellitus, hypertension, cardiogenic shock, congestive heart failure, syncope, poor LVEF, MI, stroke, renal failure, angina, chronic obstructive pulmonary disease, peripheral vascular disease, reoperative surgery, concomitant coronary artery bypass grafting (CABG), left main disease, and ischemic mitral valve pathology. Patients who had mitral valve replacement had a higher incidence of LCOS compared with patients who had mitral valve repair. No significant differences were observed among the types of mitral valve lesion: stenosis, regurgitation, or mixed. Only a small proportion of patients

\section{Prevalence of low cardiac output syndrome (LCOS)}

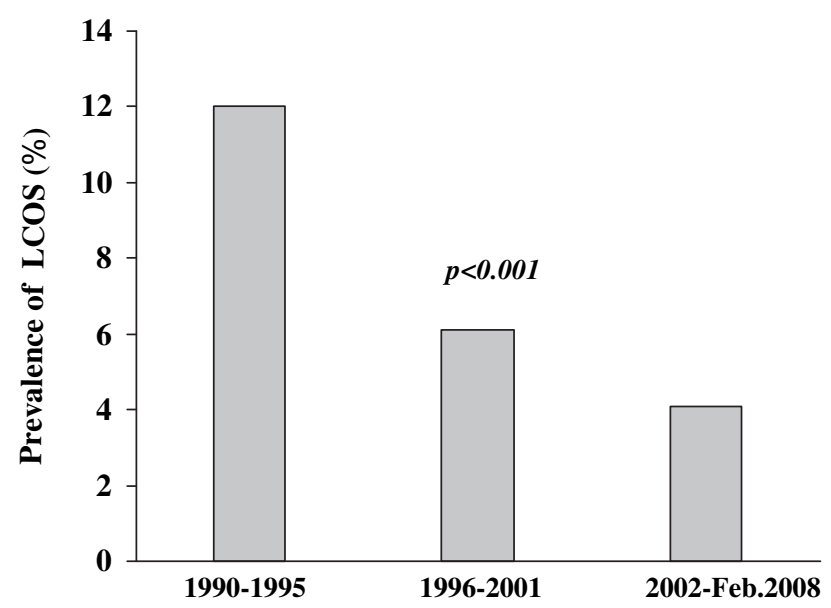

FIGURE 1. Prevalence of low cardiac output syndrome (LCOS). 
TABLE 1. Distribution of preoperative variables

\begin{tabular}{|c|c|c|c|}
\hline Variable & No $\operatorname{LCOS}(\%)$ & $\operatorname{LCOS}(\%)$ & $P$ value \\
\hline No. of patients & 2820 & 213 & \\
\hline \multicolumn{4}{|l|}{ Year of operation } \\
\hline 1990-1995 & 26.4 & 47.4 & $<.001$ \\
\hline 1996-2001 & 37.1 & 31.8 & \\
\hline 2002-February 2008 & 36.5 & 20.8 & \\
\hline Age (y) & $59 \pm 14$ & $64 \pm 12$ & $<.001$ \\
\hline \multicolumn{4}{|l|}{ Sex } \\
\hline Male & 54.4 & 49.8 & .2 \\
\hline Female & 45.6 & 50.2 & \\
\hline \multicolumn{4}{|l|}{ Body surface area } \\
\hline$\leq 1.7 \mathrm{~m}^{2}$ & 28.1 & 37.3 & .009 \\
\hline$>1.7 \mathrm{~m}^{2}$ & 71.3 & 62.7 & \\
\hline \multicolumn{4}{|l|}{ NYHA class } \\
\hline I & 10.3 & 1.9 & $<.001$ \\
\hline II & 26.4 & 9.9 & \\
\hline III & 42.4 & 26.7 & \\
\hline IV & 20.9 & 61.5 & \\
\hline Diabetes mellitus & 9.8 & 18.3 & $<.001$ \\
\hline Hypertension & 32.3 & 39.3 & .03 \\
\hline Dyslipidemia & 28.8 & 31.4 & .4 \\
\hline Cardiogenic shock & 1.9 & 17.5 & $<.001$ \\
\hline Congestive heart failure & 54.9 & 77.8 & $<.001$ \\
\hline Syncope & 2.2 & 9.4 & $<.001$ \\
\hline LVEF & & & $<.001$ \\
\hline$>60 \%$ & 55.6 & 24.1 & \\
\hline $40 \%$ to $60 \%$ & 31.9 & 38.6 & \\
\hline$<40 \%$ & 12.5 & 37.3 & \\
\hline Myocardial infarction & 3.1 & 22.2 & $<.001$ \\
\hline Stroke & 10.4 & 15.6 & .02 \\
\hline Renal failure & 1.4 & 7 & $<.001$ \\
\hline Angina & 19.2 & 48.8 & $<.001$ \\
\hline $\begin{array}{l}\text { Chronic obstructive } \\
\text { pulmonary disease }\end{array}$ & 5.1 & 11.3 & .0002 \\
\hline Peripheral vascular disease & 4.9 & 18.8 & $<.001$ \\
\hline $\begin{array}{l}\text { Reoperative surgical } \\
\text { intervention }\end{array}$ & 16.2 & 28.2 & $<.001$ \\
\hline Concomitant CABG & 26.9 & 57.3 & $<.001$ \\
\hline Left main disease & 2.9 & 10.8 & $<.001$ \\
\hline \multicolumn{4}{|l|}{ Urgency of operation } \\
\hline Elective & 77.7 & 38.5 & $<.001$ \\
\hline Same hospital & 16.1 & 27.7 & \\
\hline Urgent/emergency & 6.2 & 33.8 & \\
\hline \multicolumn{4}{|l|}{ Mitral valve surgery } \\
\hline Repair & 52.3 & 22 & $<.001$ \\
\hline Replacement & 47.7 & 78 & \\
\hline \multicolumn{4}{|c|}{ Mitral valve/prosthesis lesion (\%) } \\
\hline Stenosis & 10.8 & 10.5 & .7 \\
\hline Regurgitation & 77.1 & 78.6 & \\
\hline Mixed & 11.2 & 9.5 & \\
\hline $\begin{array}{l}\text { Ischemic mitral } \\
\text { valve pathology }\end{array}$ & 10.8 & 36.9 & $<.001$ \\
\hline \multicolumn{4}{|l|}{ Infective endocarditis (\%) } \\
\hline Active or active, abscess & 3 & 4.2 & .3 \\
\hline
\end{tabular}

LCOS, Low cardiac output syndrome; NYHA, New York Heart Association; LVEF, left ventricular ejection fraction; $C A B G$, coronary artery bypass grafting. presented with active endocarditis with or without an abscess, and the proportion was similar between the groups.

\section{Intraoperative Data}

Details of operative procedures are listed in Table 2. Patients with LCOS had smaller body surface areas and received a higher proportion of valve replacements. Mitral valve annular reconstruction and chordal preservation were higher in patients who had LCOS. However, the use of polytetrafluoroethylene (Gore-Tex; W. L. Gore \& Associates, Inc, Austin, Tex) sutures was higher in patients without LCOS. Durations of CPB and crossclamp time were longer in patients with LCOS.

\section{Postoperative Outcomes}

The overall mortality rate was $3.4 \%(\mathrm{n}=102)$. Among the 102 deaths, 82 patients died of cardiac reasons, and 20 patients died of noncardiac causes. In the LCOS group $83 \%(53 / 64)$ of patients experienced cardiac deaths, whereas in the non-LCOS group 76\% (29/38) had cardiac deaths. Operative mortality was higher in patients with LCOS $(30 \%)$ than in patients without LCOS $(1.3 \%, P<.001)$.

Postoperative length of stay and hospital outcomes are summarized in Figures 2 and 3. The LCOS group required longer ventilatory support and longer postoperative intensive care unit and hospital stay compared with the non-LCOS group (Figure 2). The incidence of postoperative complications, such as stroke, MI, reoperation for bleeding, and renal failure, was higher in patients with LCOS than in patients without LCOS (Figure 3). Patients with LCOS also had a significantly higher rate of pulmonary complications $(35 \%$ vs $10 \%, P<.001)$ and sepsis $(11 \%$ vs $0.9 \%, P<.001)$.

\section{Predictors of LCOS}

Multivariable logistic regression analysis identified 7 independent predictors of LCOS: small body surface area,

TABLE 2. Distribution of intraoperative variables

\begin{tabular}{lccc}
\hline \multicolumn{1}{c}{ Variable } & No LCOS $(\%)$ & LCOS $(\%)$ & $P$ value \\
\hline No. of patients & & & \\
Valve type & & & \\
$\quad$ Mechanical & 30.2 & 41.3 & $<.001$ \\
$\quad$ Bioprostheses & 17.5 & 36.6 & \\
$\quad$ Valve repairs & 52.3 & 22.1 & \\
Body surface area $\left(\mathrm{m}^{2}\right)$ & $1.83 \pm 0.24$ & $1.78 \pm 0.23$ & .006 \\
Mitral valve & 3.8 & 8.9 & $<.001$ \\
$\quad$ & & & \\
$\quad$ Chnular reconstruction & & & \\
$\quad$ Posterior only & 16.2 & 25 & $<.001$ \\
$\quad$ Anterior and posterior & 11.5 & 22.5 & \\
Use of PTFE sutures & 44.5 & 22.2 & $<.001$ \\
Duration of CPB (min) & $95 \pm 36.5$ & $141 \pm 54.2$ & $<.001$ \\
Duration of XCL (min) & $73 \pm 30.3$ & $98 \pm 39.5$ & $<.001$ \\
\hline LCOS, Low cardiac output & syndrome; PTFE, polytetrafluoroethylene; $C P B$, \\
cardiopulmonary bypass; XCL, aortic crossclamp. & &
\end{tabular}




\section{Mean Length of stay}

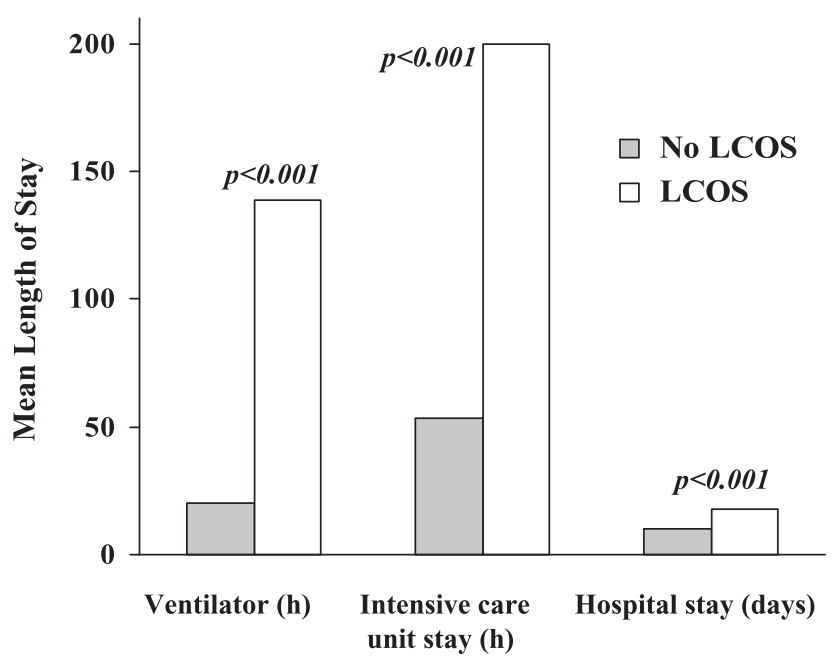

FIGURE 2. Mean length of stay. $L C O S$, Low cardiac output syndrome.

emergency or urgent operation, LVEF of less than $40 \%$, earlier year of operation, NYHA class IV, ischemic mitral valve pathology, and duration of CPB. Table 3 presents the odds ratios, $95 \%$ confidence intervals, and $P$ values associated with the above-mentioned variables. The stepwise logistic model was robust, with an area under the receiver operating characteristic of 0.84 and a HosmerLemeshow goodness-of-fit $P$ value of .42, indicating good model discrimination and calibration.

\section{Operative Mortality}

The results of univariate analysis showed that operative mortality was significantly higher in diabetic patients $(6.6 \%$ vs $2.9 \%, P<.001)$, patients with hypertension $(4.7 \%$ vs

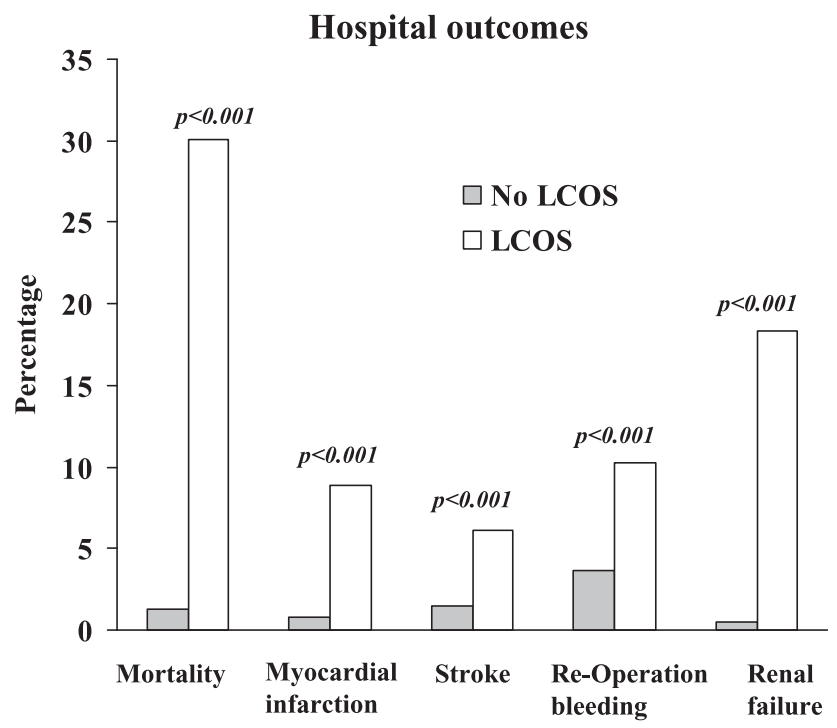

FIGURE 3. Hospital outcomes. LCOS, Low cardiac output syndrome.
TABLE 3. Multivariable predictors of low cardiac output syndrome

\begin{tabular}{lccc}
\hline \multicolumn{1}{c}{ Variable } & Odds ratio & $\mathbf{9 5} \%$ CI & $\boldsymbol{P}$ value \\
\hline $\begin{array}{l}\text { Urgent/emergency vs elective } \\
\text { operation }\end{array}$ & 2.9 & $1.6-5$ & .0002 \\
$\begin{array}{l}\text { Earlier year } \\
\quad \text { of operation, 1990-1995 vs }\end{array}$ & 2.4 & $1.5-3.7$ & $<.001$ \\
$\quad$ 2002-2007 & & & \\
$\quad \begin{array}{l}\text { Left ventricular } \\
\quad \text { ejection fraction }<40 \%\end{array}$ & 2.1 & $1.3-3.3$ & .004 \\
NYHA class IV & 2 & $1.2-3.2$ & .005 \\
BSA $\leq 1.7$ vs $>1.7 \mathrm{~m}^{2}$ & 1.6 & $1.2-2.3$ & .005 \\
$\quad \begin{array}{l}\text { Ischemic mitral } \\
\quad \text { valve pathology }\end{array}$ & 1.6 & $1.1-2.4$ & .02 \\
$\quad$ Duration of CPB & 1.02 & $1.01-1.02$ & $<.001$ \\
\hline
\end{tabular}

$C I$, Confidence interval; $N Y H A$, New York Heart Association; $B S A$, body surface area; $C P B$, cardiopulmonary bypass.

$2.6 \%, P=.002)$, patients undergoing emergency or urgent operations $(17.5 \%$ vs $1.3 \%, P<.001)$, patients with an LVEF of less than $40 \%(9.7 \%$ vs $1.4 \%, P<.001)$, patients with NYHA class IV symptoms $(9.5 \%$ vs $1.4 \%, P<.001)$, patients who had a preoperative stroke or transient ischemic attack $(5.8 \%$ vs $3.1 \%, P=.009)$, patients with peripheral vascular disease $(14 \%$ vs $2.7 \%, P<.001)$, patients with congestive heart failure $(4.8 \%$ vs $1.4 \%, P<.001)$, patients with chronic obstructive pulmonary disease $(8.8 \%$ vs $3 \%$, $P<.001)$, patients who had preoperative shock $(29.4 \%$ vs $2.6 \%, P<.001)$, patients who had preoperative MI $(18.5 \%$ vs $2.6 \%, P<.001)$, patients with preoperative renal failure $(30.4 \%$ vs $2.9 \%, P<.001)$, patients undergoing a repeat operation $(6.6 \%$ vs $2.7 \%, P<.001)$, patients with left main disease $(10.6 \%$ vs $3.1 \%, P<.001)$, patients with infective endocarditis $(9.6 \%$ in patients with active endocarditis or active abscess vs $3.2 \%$ in patients with remote or no endocarditis, $P<.001)$, patients undergoing concomitant CABG $(6.8 \%$ vs $2 \%, P<.001)$, patients with ischemic mitral valve pathology $(9.8 \%$ vs $2.4 \%, P<.001)$, patients who had mitral valve replacement compared with mitral valve repair $(5.7 \%$ vs $0.99 \%, P<.001$ ), and patients in whom no polytetrafluoroethylene sutures were used $(5 \%$ vs $0.93 \%, P<.001)$. Operative mortality in patients who had postoperative complications are summarized in Table 4.

Patients who died postoperatively were older ( $66 \pm 14$ vs $59 \pm 14$ years, $P<.001$ ), had smaller body surface areas $\left(1.78 \pm 0.26\right.$ vs $\left.1.83 \pm 0.24 \mathrm{~m}^{2}, P=.03\right)$, required longer CPB times $(155 \pm 58$ vs $96 \pm 38$ minutes, $P<.001)$, had a longer postoperative intensive care unit stay $(230 \pm 302$ vs $58 \pm 90$ hours, $P<.001$ ), required more hours of ventilator support ( $185 \pm 266$ vs $23 \pm 116$ hours, $P<.001)$, and stayed longer in the hospital postoperatively $(12.8 \pm 15 \mathrm{vs}$ $10.3 \pm 7.7$ days, $P=.03$ ).

\section{Predictors of Operative Mortality}

Stepwise logistic regression analysis identified timing of the operation, small body surface area, nonuse of 
TABLE 4. Postoperative complications

\begin{tabular}{lccc}
\multicolumn{1}{c}{$\begin{array}{c}\text { Postoperative } \\
\text { complication }\end{array}$} & No. of patients & Associated operative \\
mortality (\%) & P value \\
\hline Myocardial infarction & 40 & 27.5 & $<.001$ \\
Stroke & 55 & 23.6 & $<.001$ \\
Re-exploration & & & $<.001$ \\
Bleeding & 125 & 7.2 & \\
Tamponade & 31 & 19.3 & \\
Redo operation & 14 & 0 & \\
Shock/arrest & 10 & 70 & \\
Infection & 8 & 12.5 & \\
Dehiscence & 4 & 26.7 & \\
Other & 15 & 0 & $<.001$ \\
Sepsis & 48 & 37.5 & $<.001$ \\
Pulmonary complications & 359 & 11.4 & \\
Renal failure & 52 & 69.2 & \\
\hline
\end{tabular}

polytetrafluoroethylene sutures, duration of $\mathrm{CPB}$, and increasing age as 6 independent predictors of operative mortality. Odds ratios associated with these variables, along with 95\% confidence intervals and $P$ values, are provided in Table 5. The logistic regression model for operative mortality had good model discrimination, with an area under the curve of 0.89 , and good model calibration, with a HosmerLemeshow goodness-of-fit $P$ value of .35 .

\section{DISCUSSION}

The present study examined the clinical outcomes of a large consecutive series of patients undergoing mitral valve replacement or repair over an 18-year period. We have not found any other articles in the literature identifying the predictors of LCOS in patients undergoing mitral valve surgery. The prevalence of LCOS decreased over time, as reported previously in our published article on examining the predictors of LCOS in aortic valve operations. ${ }^{1}$ However, the postoperative morbidity and mortality associated with LCOS continues to be significant, as shown in Figure 3. Also, the mortality associated with the development of LCOS is on the increase, from $23 \%(23 / 100)$ in the earliest era to $35 \%(16 / 46)$ in the most recent era.

The effect of LCOS in a valvular population is more dramatic than that reported in patients undergoing isolated CABG. $^{2}$ Compared with a 17 -fold increase in patients undergoing $\mathrm{CABG}$, LCOS portended a 38-fold increase in mortality after aortic valve surgery and a 30-fold increase in this study. ${ }^{1}$ Although the development of LCOS was associated with a significant increase in operative mortality, from $1.3 \%$ to $30 \%$, the independent predictors of LCOS and mortality were not alike. In comparison with similar studies performed by our group in patients undergoing aortic valve surgery or isolated CABG, the predictors of LCOS after mitral valve surgery are significantly different.

In this patient population the most significant predictor of LCOS and operative mortality was the timing of the
TABLE 5. Multivariable predictors of operative mortality

\begin{tabular}{lccc}
\hline \multicolumn{1}{c}{ Variable } & Odds ratio & $\mathbf{9 5} \% \mathbf{C I}$ & $\boldsymbol{P}$ value \\
\hline $\begin{array}{l}\text { Urgent/emergency vs elective } \\
\text { operation }\end{array}$ & 7.1 & $3.9-12.7$ & $<.001$ \\
$\begin{array}{l}\text { Same-day hospitalization } \\
\quad \text { vs elective operation }\end{array}$ & 2 & & .02 \\
Renal failure & 4.3 & $2-9.4$ & $<.001$ \\
$\begin{array}{l}\text { Nonuse of PTFE sutures } \\
\text { Any reoperative }\end{array}$ & 2.1 & $1.1-3.9$ & .03 \\
$\quad$ surgical intervention & 1.8 & $2-9.4$ & $<.001$ \\
$\begin{array}{l}\text { Duration of CPB } \\
\text { Increasing age }\end{array}$ & 1.02 & $1.016-1.024$ & $<.001$ \\
\hline CI, Confidence interval; $P T F E$, polytetrafluoroethylene; $C P B$, cardiopulmonary \\
bypass.
\end{tabular}

operation. Patients undergoing operations on an urgent or emergency basis had significantly higher rates of LCOS and operative mortality. These patients are likely to have several other comorbidities, which might lead to a higher incidence of LCOS and operative mortality. Our results are in agreement with published reports by Nowicki and colleagues, ${ }^{5}$ who reported an urgent and emergency presentation as one of the most important risk factors for death after mitral valve surgery. Similarly, Jamieson and associates, ${ }^{6}$ who developed risk strata for postoperative mortality after cardiac valve replacement, also identified emergency status as one of the most important predictors.

Earlier year of operation emerged as one of the significant predictors of LCOS, which is consistent with our previously documented improvements in cardiac surgical outcomes over time. ${ }^{1,7}$ Decreased LVEF came out as one of the significant predictors of LCOS, but the influence of LVEF is less significant in patients undergoing mitral valve surgery (odds ratio, 2.1) compared with the CABG (odds ratio, 5.7) or aortic valve (odds ratio, 3.6) groups, as published in our previous reports. ${ }^{3,4}$ In our study poor preoperative LVEF is associated with a higher incidence of LCOS in patients with mitral insufficiency than in patients with mitral stenosis ( $21 \%$ vs $10.3 \%$, respectively). In a recent study published by Mirabel and coworkers, ${ }^{8}$ impaired LVEF is reported as one of the factors to deny surgical intervention in patients with severe symptomatic mitral regurgitation (MR). However, the authors do not justify the decision according to current knowledge based on American College of Cardiology/American Heart Association guidelines. Furthermore, low LVEF is found to be a predictive variable of sudden mortality $^{9-11}$ and late perioperative mortality ${ }^{12}$ in patients with MR. Unfortunately, MR can mask underlying LV dysfunction. Although noninvasive assessments of LV function might appear to be normal, often, LV function is impaired, which manifests itself after mitral competence is restored.

NYHA class IV emerged as one of the predictors of LCOS but not operative mortality. In fact, of the many studies that reported risk factors for operative mortality after mitral valve 
surgery, NYHA class IV is commonly reported as one of the major risk factors. These results confirm the previous observations that perioperative outcomes are usually worse in patients with severe symptomatic conditions. ${ }^{13-16}$ Smaller body surface area was also attributed to a higher incidence of LCOS. Previous studies in patients undergoing CABG have hypothesized an increased risk in female patients because of their smaller body size and correspondingly small coronary anatomy. ${ }^{17,18}$ The relationship between body surface area and LCOS in a valvular population is unclear. Kenchaiah and colleagues ${ }^{19}$ reported that patients with a body mass index (BMI) of less than 23 enrolled in the Candesartan in Heart Failure: Assessment of Reduction in Mortality in Morbidity study had a significantly poorer survival. Accurate BMI data were available for $2601(86 \%)$ members of this population, and of these, $698(27 \%)$ had a BMI of less than 23. These data suggest that a significant proportion of our patients might have had cardiac cachexia reflecting the end stage of their valvular disease.

Ischemic mitral valve pathology also emerged as a significant risk factor for LCOS. It has been well documented that patients with ischemic MR have a worse survival than patients without ischemic MR. ${ }^{20-22}$ Importantly, postoperative survival is inversely correlated to the degree of ischemic $\mathrm{MR}^{20}$

Duration of CPB also emerged as an independent risk factor for postoperative LCOS and mortality. Longer CPB times likely act as a surrogate for technical difficulties during surgical intervention or poor myocardial function requiring longer reperfusion times. The fact that aortic crossclamp time did not emerge as a predictor likely supports the latter hypothesis.

Apart from duration of CPB time and the urgency of the operation, which are mentioned above, renal failure, nonuse of polytetrafluoroethylene sutures, previous cardiac surgery, and increasing age significantly predicted operative mortality in the present patient population.

Renal failure and previous surgical intervention are widely reported as major risk factors of operative mortality in cardiac valve operations. Jamieson and assocoiates ${ }^{6}$ published independent predictors of operative mortality in 86,580 patients undergoing valve replacements using the Society of Thoracic Surgeons database. Their study identified renal failure and reoperations as high-level risk factors. Similarly, Herzog and cowrkers ${ }^{23}$ identified more than 5000 dialysis patients undergoing aortic valve surgery, mitral valve surgery, or both through the US Renal Data System over a 20 -year period. The perioperative mortality was greater than $20 \%$, and the 2-year survival rate was only $40 \%$, irrespective of whether a mechanical or tissue valve was implanted. Several studies have examined various renal protective strategies in an isolated CABG population; however, no single strategy has emerged as clearly beneficial. ${ }^{24}$ It is unclear whether perioperative dopamine, vasopressin, or $\mathrm{N}$-acetylcysteine would prove to be more beneficial in patients undergoing mitral valve surgery.
Similar to renal failure and reoperations, advanced age is also reported as one of the most important predictors of operative mortality in patients undergoing mitral valve operations. ${ }^{25-28}$ These reports emphasize the significance of age as one of the important factors in clinical decision making. Indeed, Mirabel and coworkers ${ }^{8}$ reported advance age as one of the factors to deny surgical intervention in patients with severe MR in the Euro heart survey on valvular disease.

Interestingly, the use of polytetrafluoroethylene artificial chordae was found to protect against the development of both postoperative low output syndrome and operative mortality. When stratified by repair or replacement, polytetrafluoroethylene chordae were found to be beneficial in both groups. We have previously reported that the preservation of chordae tendinae leads to improved early and late outcomes after mitral valve replacement, presumably because of improved papillary muscle-annular interactions. ${ }^{29,30}$ However, the mechanism by which artificial chordae improves LV function and reduces operative mortality in patients undergoing mitral valve repair is unclear and deserves further investigation. Although the use of polytetrafluoroethylene sutures was practiced throughout the duration of the study, use did increase $(1990-1995,37 \%$; 1996 2001, 43\%; and 2002-2007, 48\%; $P<.001$ ).

In summary, this study is the first to distinguish the preoperative predictors of postoperative LCOS from those of operative mortality in a population of patients undergoing mitral valve surgery. In agreement with our previous study examining aortic valve surgery, the development of postoperative LCOS is associated with significant morbidity and mortality.

The clinical implications of this study are multifaceted. Preoperative risk profiling and patient selection will always benefit from repeated analyses of institutional results. However, an additional objective of this study was to predict those patients who might require mechanical circulatory support in the early postoperative period. During the time period of this study, we did not offer mechanical circulatory support to those patients with postcardiotomy shock unless the patient was prescreened before intervention and found to be a suitable transplant candidate. No patient who underwent mitral valve surgery with "left ventricular assist device backup" required temporary mechanical support other than an IABP.

Despite the prospective nature of the data collection, this study remains a retrospective review of a single center's experience and suffers from all of the caveats of such a study. We did not examine the effect of altered surgical decision making because of perceived risk (eg, repair vs replace or mechanical vs tissue valve). Furthermore, although we restricted our analysis to isolated mitral valve surgery, there are several diverse patient populations within our cohort, each with a varied level of operative risk (eg, myxomatous vs ischemic). 
In this study urgent surgical intervention, advanced NYHA functional class, poor preoperative LVEF, ischemic cause, and small body surface area were predictors of LCOS. Therefore these patients remain at risk for requiring mechanical circulatory support and should be screened appropriately preoperatively (if possible) to determine ultimate disposition. This would facilitate intraoperative decision making with respect to the use of a long-term implantable device versus short-term paracorporeal support. In addition, such a screening process would highlight the need for strategic placement of proximal coronary bypass grafts in patients with ischemic MR, allowing for the potential subsequent insertion of an left ventricular assist device outflow graft. We suggest preoperative "optimization" of high-risk patients undergoing mitral surgery who might benefit from diuresis, afterload reduction, and time to recover from an acute ischemic insult. It is strikingly evident that the development of postoperative LCOS in patients undergoing mitral valve surgery has a dramatic effect on additional morbidity and mortality, highlighting the need for a cautious and planned approach in high-risk subjects.

\section{References}

1. Maganti MD, Rao V, Borger MA, Ivanov J, David TE. Predictors of low cardiac output syndrome after isolated aortic valve surgery. Circulation. 2005; 112(suppl):I448-52.

2. Rao V, Ivanov J, Weisel RD, Ikonomidis JS, Christakis GT, David TE. Predictors of low cardiac output syndrome after coronary artery bypass. J Thorac Cardiovasc Surg. 1996;112:38-51.

3. Rao V, Christakis GT, Weisel RD, Buth KJ, Ikonomidis JS, Shirai T, et al. Changing pattern of valve surgery. Circulation. 1996;94:113-20.

4. Weisel RD, Burns RJ, Baird RJ, Hilton JD, Ivanov J, Mickle DA, et al. Optimal postoperative volume loading. J Thorac Cardiovasc Surg. 1983;85:552-63.

5. Nowicki ER, Birkmeyer NJ, Weintraub RW, Leavitt BJ, Sanders JH, Dacey LJ, et al. Multivariable prediction of in-hospital mortality associated with aortic and mitral valve surgery in Northern New England. Ann Thorac Surg. 2004;77: 1966-77.

6. Jamieson WR, Edwards FH, Schwartz M, Bero JW, Clark RE, Grover FL. Risk stratification for cardiac valve replacement. National Cardiac Surgery Database. Database Committee of The Society of Thoracic Surgeons. Ann Thorac Surg. 1999;67:943-51.

7. Borger MA, Ivanov J, Weisel RD, Peniston CM, Mickleborough LL, Rambaldini G, et al. Decreasing incidence of stroke during valvular surgery. Circulation. 1998;98:137-43.

8. Mirabel M, Iung B, Baron G, Messika-Zeitoun D, De'taint D, Vanoverschelde J$\mathrm{L}$, et al. What are the characteristics of patients with severe, symptomatic, mitral regurgitation who are denied surgery? Eur Heart J. 2007;28:1358-65.

9. Delahaye JP, Gare JP, Viguier E, Delahaye F, De Gevigney G, Milon H. Natural history of severe mitral regurgitation. Eur Heart J. 1991;12(suppl B):5-9.

10. Ling LH, Enriquez-Sarano M, Seward JB, Tajik AJ, Schaff HV, Bailey KR, et al. Clinical outcome of mitral regurgitation due to flail leaflet. N Engl J Med. 1996; $335: 1417-23$.
11. Avierinos JF, Gersh BJ, Melton LJ 3rd, Bailey KR, Shub C, Nishimura RA, et al. Natural history of mitral valve prolapse in the community. Circulation. 2002;106: 1355-61.

12. Enriquez-Sarano M, Tajik AJ, Schaff HV, Orszulak TA, Bailey KR, Frye RL. Echocardiographic prediction of survival after surgical correction of organic mitral regurgitation. Circulation. 1994;90:830-7.

13. Abdelnoor M, Fjeld NB, Vaage K, Svennevig JL, Klingen G, Wickstrom E, et al. Risk factors for morbidity and mortality in mitral valve replacement. Eur J Cardiothorac Surg. 1990;4:425-30.

14. Sand ME, Naftel DC, Blackstone EH, Kirklin JW, Karp RB. A comparison of repair and replacement for mitral valve incompetence. $J$ Thorac Cardiovasc Surg. 1987;94:208-19.

15. Chaffin JS, Daggett WM. Mitral valve replacement: a nine-year follow-up of risks and survivals. Ann Thorac Surg. 1979;27:312-9.

16. Scott WC, Miller DC, Haverich A, Mitchell RS, Oyer PE, Stinson EB, et al. Operative risk of mitral valve replacement: discriminant analysis of 1329 patients. Circulation. 1985;72(suppl II):II108-19.

17. Christakis GT, Weisel RD, Buth KJ, Fremes SE, Rao V, Panagiotopoulos KP, et al. Is body size the cause for poor outcomes of coronary artery bypass operations in females? J Thorac Cardiovasc Surg. 1995;110:1344-58.

18. Abramov D, Tamariz MG, Sever JY, Christakis GT, Bhatnagar G, Heenan AL, et al. The influence of gender on the outcome of coronary artery bypass surgery. Ann Thorac Surg. 2000;70:800-5.

19. Kenchaiah S, Pocock SJ, Wang D, Finn PV, Zornoff LA, Skali H, et al. Body mass index and prognosis in patients with chronic heart failure: insights from the Candesartan in Heart Failure: Assessment of Reduction in Mortality in Morbidity (CHARM) program. Circulation. 2007;116:627-36.

20. Grigioni F, Enriquez-Sarano M, Zehr KJ, Bailey KR, Tajik AJ. Ischemic mitral regurgitation long-term outcome and prognostic implications with quantitative Doppler assessment. Circulation. 2001;103:1759-64.

21. Ellis SG, Whitlow PL, Raymond RE, Schneider JP. Impact of mitral regurgitation on long-term survival after percutaneous coronary intervention. Am J Cardiol. 2002;89:315-8.

22. Ling LH, Enriquez Sarano M, Seward JB, Orszulak TA, Schaff HV, Bailey KR, et al. Early surgery in patients with mitral regurgitation due to flail leaflets; a long-term outcome study. Circulation. 1997;96:1819-25.

23. Herzog CA, Ma JZ, Collins AJ. Long-term survival of dialysis patients in the United States with prosthetic heart valves: should ACC/AHA practice guidelines on valve selection be modified? Circulation. 2002;105:1336-41.

24. Wijeysundera DN, Karkouti K, Beattie WS, Rao V, Ivanov J. Improving the identification of patients at risk of postoperative renal failure following cardiac surgery. Anaesthesiology. 2006;104:65-72.

25. Teoh KH, Ivanov J, Weisel RD. The cardiovascular surgeons at the Toronto General Hospital. Determinants of survival and valve failure after mitral valve replacement. Eur J Cardiothorac Surg. 1990;4:425-30.

26. Sand ME, Naftel DC, Blackstone EH, Kirklin JW, Karp RB. A comparison of repair and replacement for mitral valve incompetence. J Thorac Cardiovasc Surg. 1987;94:208-19.

27. Chaffin JS, Daggettt WM. Mitral valve replacement: a nine-year follow-up of risks and survivals. Ann Thorac Surg. 1985;39:346-52.

28. Veterans Administration Cooperative study on valvular heart disease. clinical, hemodynamic and angiographic predictors of operative mortality in patients undergoing single valve replacement. J Thorac Cardiovasc Surg. 1987;93: 884-97.

29. Rao V, Komeda K, Weisel RD, Ikonomidis JS, Ivanov J, David TE. Results of represervation of the chordae tendinae during redo mitral valve replacement. Ann Thorac Surg. 1996;62:179-83.

30. Komeda M, David TE, Rao V, Sun Z, Weisel RD, Burns RJ. Late hemodynamic effects of the preserved papillary muscles during mitral valve replacement. Circulation. 1994;90:II190-4. 